\title{
Paternal characteristics associated with maternal periconceptional use of folic acid supplementation
}

\author{
Jan Helge Seglem Mortensen ${ }^{1,2^{*}}$ (D), Nina Øyen ${ }^{1,3}$, Roy M. Nilsen ${ }^{4}$, Tatiana Fomina', Steinar Tretli ${ }^{5}$ \\ and Tone Bjørge $e^{1,5}$
}

\begin{abstract}
Background: Maternal predictors of folic acid (FA) supplementation use to reduce offspring risk of neural tube defects are well known, while paternal determinants for maternal FA use are less known. Such knowledge is important to increase women's compliance to recommended periconceptional FA use.

Methods: In a nation-wide study of 683,785 births registered in the Medical Birth Registry of Norway during 1999-2010, the associations between paternal characteristics (age, education, occupation, country of origin) and maternal FA use were estimated by relative risks (RR) with 95\% confidence intervals (CI), using logbinomial regression.

Results: Maternal FA use before and during pregnancy (adequate FA use) was found in 16\% of the births. The association between paternal age and adequate FA use was inversely U-shaped; adjusted RRs for adequate FA use were 0.35 (95\% Cl 0.28-0.43) and 0.72 (95\% Cl 0.71-0.74) for paternal age $<20$ and $\geq 40$ years, respectively, comparing age 30-34 years. Compulsory education (1-9 years) among fathers was compared to tertiary education; the RR was 0.69 ( $95 \% \mathrm{Cl}$ 0.68-0.71) for adequate FA use. The lower risk of adequate FA use for paternal compulsory education was present in all categories of maternal education. Occupation classes other than "Higher professionals" were associated with decreased risk of adequate FA use, compared with the reference "Lower professionals". RR for adequate FA use was 0.58 ( $95 \% \mathrm{Cl}$ 0.56-0.60) comparing fathers from "Low/middle-income countries" with fathers born in Norway.

Conclusion: Adequate FA use in the periconceptional period was lower when fathers were younger or older than 30-34 years, had shorter education, had manual or self-employed occupations, or originated from low/ middle-income countries. Partners may contribute to increase women's use of periconceptional FA supplementation.
\end{abstract}

Keywords: Pregnancy, Supplement use, Folic acid, Norway

\section{Background}

Folate is necessary in foetal development, and folic acid (FA) supplementation is widely acknowledged to reduce the risk of neural tube defects (NTDs) [1-5]. FA is the synthetic form of the B-vitamin folate, which is essential in the synthesis of DNA, methylation, and DNA repair

\footnotetext{
* Correspondence: jan.mortensen@uib.no

${ }^{1}$ Department of Global Public Health and Primary Care, University of Bergen, Kalfarveien 31, N-5018 Bergen, Norway

${ }^{2}$ Department of Obstetrics and Gynecology, Haukeland University Hospital, Bergen, Norway

Full list of author information is available at the end of the article
}

[6]. Start of FA supplementation prior to conceiving is important in order to reduce the risk of NTDs because the neural tube closes between 21 and 28 days after conception [7].

Randomized clinical trials and non-randomized intervention trials have demonstrated that periconceptional FA use reduces the risk of NTDs [1-3]. Recent studies have reported that FA is associated with protection against other neurodevelopmental disorders and some severe pregnancy complications [8-10]. The protective effect of FA on NTDs has led health authorities

(C) The Author(s). 2018 Open Access This article is distributed under the terms of the Creative Commons Attribution 4.0 International License (http://creativecommons.org/licenses/by/4.0/), which permits unrestricted use, distribution, and 
in several countries, including Norway, to recommend women to take FA supplements before pregnancy and in early pregnancy [11-13].

Many countries in Europe, including Norway, have performed information campaigns to increase the use of periconceptional FA supplementation among women planning pregnancy [14-16]. Presently there is no mandatory folic acid food fortification in Norway [17]. Official Norwegian guidelines from 1998, states that all women planning their pregnancy should use $0.4 \mathrm{mg}$ FA daily from 1 month before pregnancy and throughout the first 2-3 months of pregnancy to reduce the risk of NTDs [12]. However, the proportion of preconception FA supplementation use in Norway is still too low [18] and by 2015 it was $33 \%$ [19].

Previous studies have identified maternal factors associated with inadequate FA in the periconceptional period, such as low maternal age, shorter education, single parenthood, unplanned pregnancy, lower parity, smoking, alcohol use, less physical activity, or originating from a foreign country [15, 16, 20-24].

Since couples tend to exhibit concordant health behaviour's for dietary intake, smoking, alcohol consumption, physical activity, and body mass index (BMI) [25-27], a woman's partner may contribute to her use of periconceptional FA supplements. In fact, in an early report from the Norwegian Mother and Child Cohort Study (MoBa), 2000-2003, counting 22,500 women, FA supplements were used more frequently among women with partners with a higher education [22]. However, the study did not assess other paternal factors or combined paternal and maternal factors as to identify women with inadequate FA use.

Taking advantage of the Medical Birth Registry of Norway that to our knowledge is the only national registry with information on periconceptional use of FA supplements [28], we updated parent information with data from national registries to investigate whether paternal factors (age, education, occupation, country of origin) was associated with mothers' intake of recommended FA in pregnancy.

\section{Methods}

\section{Data-sources}

Maternal FA use before and/or during pregnancy was collected from the Medical Birth Registry of Norway (MBRN) [28]. Paternal and maternal demographic data came from the National Registry (NR). Information on paternal and maternal occupation originated from the Norwegian Labour and Welfare Administration (NAV), and we retrieved paternal and maternal educational data from the Norwegian National Education Database (NUDB) [29].
MBRN is a population-based registry containing information on all births in Norway since 1967 [28]. The registry holds demographic information on the mother and the father, the mother's health before and during pregnancy, including chronic diseases, information on in vitro fertilization (IVF), complications during pregnancy and delivery as well as information on the infant, including birth defects and other perinatal problems. Midwives and physicians attending the deliveries register the data. Since 1967, there has been mandatory reporting of all live and stillbirths from the 16 gestational week to MBRN.

NR contains demographic information on all residents in Norway since 1960, including the date of birth, country of origin, and the dates of immigration, emigration, or death [30]. NR assigns a unique personal identification number to all individuals born or immigrated to Norway, enabling accurate record linkages.

NAV was established in 2006 after governmental reorganization of the Directorate of Labour in Norway (founded in 1945), and has registered information on occupation, health status, and social benefits of all individuals with residence in Norway since 1992. The Norwegian occupational code system is based on the International Standard Classification of Occupations (ISCO), revised version from 1988 [31].

Since 1970, NUDB holds information on all individuals' education history from primary school up to doctoral studies in one database [32]. The classification is based on the Norwegian Standard Classification of Education.

\section{Maternal FA supplement use}

We constructed a binary variable for intake of FA supplement use $(0.4 \mathrm{mg} /$ day) (regardless of concomitant multivitamin use) registered in the MBRN since December 1998 onwards; adequate FA use (recommended FA supplementation before and during pregnancy), and inadequate FA use (FA supplementation only before pregnancy, or only during pregnancy, or no record of FA use).

MBRN also registers multivitamin use, but our investigation focused on periconceptional FA use as such intake was according to official guidelines.

\section{Paternal characteristics}

We used the following paternal variables in our analyses of adequate FA supplementation; paternal age $(<20,20-24,25-29,30-34,35-39,40+$ years $)$; education (Compulsory (1-9 years), Intermediate (1012 years), Tertiary (13-19 years)); occupation according to the class scheme of Erikson, Goldthorpe, and Portocarero (I Higher professionals, II Lower professionals, IIIa Higher routine, IIIb Lower routine, IV 
Other self-employed workers, V Technicians, VI Skilled, VII Semiskilled and unskilled, VIIb Agricultural, Unclassified) (EGP) [33]; and country of origin according to the classification by World Health Organization, Health statistics and information systems, Estimates for 2000-2012 (Norway, High income countries, Low/middle-income countries) [34].

\section{Covariates}

We used directed acyclic graphs (DAGs) and subject-matter knowledge to select a minimally sufficient adjustment set of variables that identify the unconfounded association of paternal characteristics on adequate maternal FA supplementation use [35-37].

The potential confounders of the paternal characteristics and maternal FA use relationship included year of childbirth (continuous), paternal age $(<20,20-24,25-$ 29, 30-34, 35-39, 40+ years), education (Compulsory, Intermediate, Tertiary), or country of origin (Norway, High-income countries, Low/middle-income countries).

Furthermore, we included maternal age $(<20,20-24$, 25-29, 30-34, 35-39, 40+ years), maternal education (Compulsory, Intermediate, Tertiary), and maternal country of origin (Norway, High-income countries, Low/ middle-income countries) as possible confounders of the associations between paternal age, education, or country of origin, and maternal adequate FA use.

Maternal smoking was not included in the final models because smoking was not considered a confounder of the association of paternal characteristics on maternal FA supplementation use [38].

\section{Study population}

During 1999-2010, 716,021 births were registered in MBRN. We excluded births (induced abortions) without information on FA or multivitamin supplementation use (2519) and births without maternal identification number (4091). For multiple births, we included data for the first birth and excluded 12,927 next born individuals. Among the remaining 696,484 births, we excluded 12,699 births without paternal identification number, leaving 683,785 live births and stillbirths for analyses.

\section{Statistical analysis}

Associations between paternal characteristics (age, education, occupation, country of origin) and maternal FA use were estimated as relative risks (RRs) with 95\% confidence intervals (CIs) by log-binomial regression, using the log-link function in Stata version 15 [39]. The 95\% CIs were based on robust variance estimation with the sandwich estimator to correct for the intra-individual correlation in women with more than one pregnancy during the study period [40]. Births with missing data on covariates were excluded from the analyses. $P$-values for overall difference between the categories of paternal characteristics were calculated using likelihood ratio tests. We evaluated and tested the potential effect modification of the association between paternal education and maternal FA use by stratification and likelihood ratio test.

\section{Results}

Our study included 683,785 births during 1999-2010. Table 1 presents the characteristics of the parents. The median ages of the fathers and mothers at childbirth were 33 and 30 years, respectively. For about $41 \%$ of the births, the mothers were primiparous, and about $2 \%$ of the births were conceived after in vitro fertilization (IVF). The majority of the births were of Norwegian-born parents $(84 \%$ of the fathers and $83 \%$ of the mothers). For about $34 \%$ of the births, the fathers had tertiary education, and for about $19 \%$ of the births, the fathers had compulsory education only. The paternal educational level varied by his country of origin. Fathers originating from low/middle-income countries generally had lower educational level compared to fathers originating from Norway and other high-income countries (not shown). Occupation classified as "Lower professionals," accounted for $22 \%$ of all the births. For about $14 \%$ of the births, the women smoked daily at the start of pregnancy, about 3\% smoked intermittently, and $67 \%$ did not smoke. Nearly $17 \%$ of the smoking data were missing.

For about $16 \%$ of all births in the study population, the mothers were assigned to the category adequate FA supplementation users. However, during 1999 through 2010, the proportion of adequate FA supplementation use increased from $4 \%$ at the start of the study period (1999) to $26 \%$ in 2010.

Table 2 presents crude and adjusted RRs for adequate maternal periconceptional FA use by paternal variables (determinants). Adjusted analyses showed an inverse "U-shaped" relationship between paternal age and adequate maternal FA supplement use where the smallest RRs were found for paternal age below 20 years (RR 0.35 (95\% CI $0.28-0.43$ )), 20-24 years (RR 0.68 (95\% CI $0.66-0.71)$ ), and 40 years and above (RR 0.72 (95\% CI 0.71-0.74)) compared to paternal age 30-34 years. Paternal compulsory education was associated with reduced risk of adequate FA use (RR 0.69 (95\% CI 0.68-0.71)) compared to paternal tertiary education. All paternal occupation classes were associated with reduced risk of adequate FA use except for "I Higher professionals", when compared to "II Lower professionals", in particular "VII Semiskilled and unskilled" (RR 0.75 (95\% CI $0.73-0.76)$ ), and "VIIb Agricultural" (RR 0.73 (95\% CI 0.69-0.78)). 
Table 1 Paternal and maternal characteristics in 683,785 births in Norway, 1999-2010

\begin{tabular}{|c|c|c|c|c|}
\hline & \multicolumn{4}{|l|}{ Births } \\
\hline & Fathers & $\%$ & Mothers & $\%$ \\
\hline Number of births & 683,785 & 100.0 & 683,785 & 100.0 \\
\hline \multicolumn{5}{|l|}{ Age } \\
\hline$<20$ & 4401 & 0.6 & 15,464 & 2.3 \\
\hline $20-24$ & 48,448 & 7.1 & 100,016 & 14.6 \\
\hline $25-29$ & 162,671 & 23.8 & 223,480 & 32.7 \\
\hline $30-34$ & 235,401 & 34.4 & 228,203 & 33.4 \\
\hline $35-39$ & 151,540 & 22.2 & 99,727 & 14.6 \\
\hline $40+$ & 81,324 & 11.9 & 16,895 & 2.5 \\
\hline \multicolumn{5}{|l|}{ Education } \\
\hline Compulsory education (1-9 years) & 130,953 & 19.2 & 125,479 & 18.4 \\
\hline Intermediate (10-12 years) & 302,384 & 44.2 & 230,320 & 33.7 \\
\hline Tertiary education (13-19 years) & 229,818 & 33.6 & 298,036 & 43.6 \\
\hline Missing data & 20,630 & 3.0 & 29,950 & 4.4 \\
\hline \multicolumn{5}{|l|}{ Occupational class ${ }^{a}$} \\
\hline I Higher professionals & 86,635 & 12.7 & 50,650 & 7.4 \\
\hline II Lower professionals & 152,781 & 22.3 & 122,804 & 18.0 \\
\hline Illa Higher routine & 77,540 & 11.3 & 197,174 & 28.8 \\
\hline Illb Lower routine & 40,070 & 5.9 & 114,795 & 16.8 \\
\hline IV Other self-employed workers & 358 & 0.1 & 119 & 0.0 \\
\hline V Technicians & 5550 & 0.8 & 1492 & 0.2 \\
\hline VI Skilled & 108,755 & 15.9 & 15,961 & 2.3 \\
\hline VII Semiskilled and unskilled & 111,584 & 16.3 & 73,994 & 10.8 \\
\hline Vllb Agricultural & 7663 & 1.1 & 2720 & 0.4 \\
\hline Unclassified & 52,824 & 7.7 & 51,264 & 7.5 \\
\hline Missing data & 40,025 & 5.9 & 52,812 & 7.7 \\
\hline \multicolumn{5}{|l|}{ Country of origin ${ }^{b}$} \\
\hline Norway & 574,602 & 84.0 & 567,241 & 83.0 \\
\hline High income countries & 33,487 & 4.9 & 30,920 & 4.5 \\
\hline Low/middle-income countries & 75,497 & 11.0 & 85,597 & 12.5 \\
\hline Missing data & 199 & 0.0 & 27 & 0.0 \\
\hline \multicolumn{5}{|l|}{ Marital status } \\
\hline Unmarried & & & 37,057 & 5.4 \\
\hline Married/Partnership & & & 634,283 & 92.8 \\
\hline Divorced & & & 3417 & 0.5 \\
\hline Missing data & & & 9028 & 1.3 \\
\hline \multicolumn{5}{|l|}{ In vitro fertilization (IVF) } \\
\hline No & & & 669,024 & 97.8 \\
\hline Yes & & & 14,761 & 2.2 \\
\hline \multicolumn{5}{|l|}{ Birth order } \\
\hline 1 & & & 280,178 & 41.0 \\
\hline 2 & & & 244,532 & 35.8 \\
\hline$\geq 3$ & & & 159,075 & 23.3 \\
\hline
\end{tabular}

Table 1 Paternal and maternal characteristics in 683,785 births in Norway, 1999-2010 (Continued)

\begin{tabular}{|c|c|c|}
\hline \multicolumn{3}{|c|}{ Maternal chronic disease $^{c}$} \\
\hline No & 623,817 & 91.2 \\
\hline Yes & 59,968 & 8.8 \\
\hline \multicolumn{3}{|c|}{ Maternal smoking before pregnancy } \\
\hline Non-smoker & 456,797 & 66.8 \\
\hline Intermittent & 18,518 & 2.7 \\
\hline Daily & 93,662 & 13.7 \\
\hline Missing data & 114,808 & 16.8 \\
\hline \multicolumn{3}{|c|}{ Maternal folic acid use in pregnancy } \\
\hline No use & 371,820 & 54.4 \\
\hline Only before & 8930 & 1.3 \\
\hline Only during & 192,169 & 28.1 \\
\hline Before and during & 110,866 & 16.2 \\
\hline \multicolumn{3}{|c|}{$\begin{array}{l}\text { aCategorized according to the class scheme of Erikson, Goldthorpe and } \\
\text { Portocarero (EGP) [33] } \\
\text { bCategorized according to the classification by World Health Organization, } \\
\text { Health statistics and information systems, Estimates for 2000-2012 [34] } \\
\text { 'Asthma, hypertension, kidney disease, chronic urinary infection, rheumatoid } \\
\text { arthritis, heart disease, epilepsy, diabetes mellitus (type I or II), and } \\
\text { thyroid disease }\end{array}$} \\
\hline
\end{tabular}

Mothers whose children's father originated from low/ middle-income countries had also a reduced risk of adequate FA use (RR 0.58 (95\% CI 0.56-0.60)) compared to fathers originating from Norway.

Table 3 presents crude and adjusted RRs with 95\% CIs of adequate FA use by maternal and paternal education. Adjusted analyses showed that adequate FA use was less likely in births were fathers had compulsory education, regardless of maternal education. The association of paternal compulsory education and recommended FA use was weakened by increasing level of maternal education. However, even when the mother had tertiary education, the association of compulsory paternal education on adequate maternal FA use was significant (RR 0.75 (95\% CI 0.73-0.77)), compared to fathers with tertiary education.

\section{Discussion}

The present population-based study $(683,785$ births during 1999-2010) showed that recommended maternal FA use was low among fathers who were young or older at their children's birth, had achieved shorter education, held a manually or self-employed occupation, or originated from low/middle-income countries. Even among mothers who had achieved higher education, recommended periconceptional maternal FA use was low among less educated fathers.

Several studies have investigated the association between maternal socio-demographic, reproductive, and medical characteristics and adherence to recommended intake of periconceptional FA. A common feature among mothers is that young age, low educational level, low 
Table 2 Relative risks (RRs) with 95\% confidence intervals (95\% Cls) of adequate maternal periconceptional folic acid supplement use (before and during pregnancy) by paternal characteristics, in 683,785 births, Norway, 1999-2010

\begin{tabular}{|c|c|c|c|c|c|c|c|c|}
\hline \multirow[b]{2}{*}{ Characteristics } & \multicolumn{2}{|c|}{$\begin{array}{l}\text { Folic acid supplementation } \\
\text { use }\end{array}$} & \multicolumn{2}{|c|}{ Unadjusted } & \multicolumn{2}{|c|}{ Adjusted for paternal factors ${ }^{a} \mathrm{~b}$} & \multicolumn{2}{|c|}{$\begin{array}{l}\text { Further adjusted for maternal } \\
\text { factors a } c\end{array}$} \\
\hline & Yes & No & $\mathrm{RR}^{*}$ & $95 \% \mathrm{Cl}$ & $\mathrm{RR}^{*}$ & $95 \% \mathrm{Cl}$ & $\mathrm{RR}^{*}$ & $95 \% \mathrm{Cl}$ \\
\hline \multicolumn{9}{|l|}{ Paternal age (years) } \\
\hline$<20$ & 86 & 4315 & 0.11 & $0.09-0.13$ & 0.10 & $0.08-0.13$ & 0.35 & $0.28-0.43$ \\
\hline $20-24$ & 3325 & 45,123 & 0.37 & $0.36-0.39$ & 0.37 & $0.36-0.38$ & 0.68 & $0.66-0.71$ \\
\hline $25-29$ & 22,886 & 139,785 & 0.76 & $0.75-0.78$ & 0.77 & $0.76-0.79$ & 0.94 & $0.93-0.96$ \\
\hline $30-34$ & 43,348 & 192,053 & 1.00 & Reference & 1.00 & Reference & 1.00 & Reference \\
\hline $35-39$ & 28,488 & 123,052 & 1.02 & $1.01-1.03$ & 0.97 & $0.96-0.99$ & 0.90 & $0.89-0.91$ \\
\hline $40+$ & 12,733 & 68,591 & 0.85 & $0.83-0.87$ & 0.80 & $0.78-0.81$ & 0.72 & $0.71-0.74$ \\
\hline \multicolumn{9}{|l|}{ Paternal education } \\
\hline Compulsory (1-10 years) & 11,694 & 119,259 & 0.40 & $0.39-0.40$ & 0.52 & $0.51-0.53$ & 0.69 & $0.68-0.71$ \\
\hline Intermediate (11-13 years) & 45,411 & 256,973 & 0.67 & $0.66-0.67$ & 0.75 & $0.74-0.76$ & 0.87 & $0.85-0.88$ \\
\hline Tertiary (14-20 years) & 51,894 & 177,924 & 1.00 & Reference & 1.00 & Reference & 1.00 & Reference \\
\hline Missing data & 1867 & 18,763 & & & & & & \\
\hline \multicolumn{9}{|l|}{ Paternal occupational class ${ }^{d}$} \\
\hline I Higher professionals & 19,957 & 66,678 & 1.05 & $1.04-1.07$ & 1.05 & $1.03-1.06$ & & \\
\hline II Lower professionals & 33,366 & 119,415 & 1.00 & Reference & 1.00 & Reference & & \\
\hline Illa Higher routine & 12,292 & 65,248 & 0.73 & $0.71-0.74$ & 0.89 & $0.88-0.91$ & & \\
\hline Illb Lower routine & 5352 & 34,718 & 0.61 & $0.59-0.63$ & 0.85 & $0.83-0.87$ & & \\
\hline IV Other self-employed workers & 60 & 298 & 0.77 & $0.61-0.97$ & 0.83 & $0.65-1.05$ & & \\
\hline V Technicians & 836 & 4714 & 0.69 & $0.65-0.74$ & 0.89 & $0.84-0.95$ & & \\
\hline VI Skilled & 15,174 & 93,581 & 0.64 & $0.63-0.65$ & 0.84 & $0.83-0.86$ & & \\
\hline VII Semiskilled and unskilled & 11,643 & 99,941 & 0.48 & $0.47-0.49$ & 0.75 & $0.73-0.76$ & & \\
\hline Vllb Agricultural & 908 & 6755 & 0.54 & $0.51-0.58$ & 0.73 & $0.69-0.78$ & & \\
\hline Unclassified & 7575 & 45,249 & 0.66 & $0.64-0.67$ & 0.96 & $0.94-0.99$ & & \\
\hline Missing data & 3703 & 36,322 & & & & & & \\
\hline \multicolumn{9}{|l|}{ Paternal country of origin ${ }^{e}$} \\
\hline Norway & 99,339 & 475,263 & 1.00 & Reference & 1.00 & Reference & 1.00 & Reference \\
\hline High income countries & 6535 & 26,952 & 1.13 & $1.10-1.16$ & 1.06 & $1.04-1.09$ & 1.06 & $1.03-1.08$ \\
\hline Low-middle-income countries & 4975 & 70,522 & 0.38 & $0.37-0.39$ & 0.35 & $0.34-0.36$ & 0.58 & $0.56-0.60$ \\
\hline Missing data & 17 & 182 & & & & & & \\
\hline
\end{tabular}

${ }^{\mathrm{a}}$ All RRs for adequate folic acid supplementation adjusted for year of childbirth (continuous)

${ }^{b}$ RRs by paternal age, no other adjustment for paternal factors; RRs by paternal education adjusted for paternal age $(<20,20-24,25-29,30-34,35-39,40+)$, paternal country of origin (Norway, high-income countries, low/middle-income countries); RRs by paternal occupation adjusted for paternal age, fathers country of origin, fathers education (compulsory, intermediate, tertiary); and RR by paternal origin of country, no other adjustment for paternal factors

${ }^{\mathrm{C}} \mathrm{RRs}$ by paternal age, further adjusted for maternal age $(<20,20-24,25-29,30-34,35-39,40+)$; RRs by paternal education, further adjusted for maternal education (compulsory, intermediate, tertiary); RRs by paternal occupation, no further adjustment for maternal factors; RRs by paternal country of origin adjusted for maternal country of origin (Norway, High-income countries, Low/middle-income countries)

${ }^{\mathrm{d} C}$ Categorized according to the class scheme of Erikson, Goldthorpe and Portocarero (EGP) [33]

${ }^{e}$ Categorized according to the classification by World Health Organization, Health statistics and information systems, Estimates for 2000-2012 [34]

${ }^{*} p$-value for difference between categories of paternal characteristics was $<0.001$ using likelihood ratio test

socioeconomic status, unplanned pregnancy, higher parity, smoking, single marital status, and non-western birthplace is the most important determinants for inadequate FA supplementation use [20-23]. Furthermore, maternal chronic diseases and IVF were positively associated with adequate periconceptional FA supplementation use $[22,38]$.
In Denmark, a cross-sectional study consisting of 22,000 pregnant women (primiparious and multiparous) showed that only $14 \%$ of the women used FA as recommended and compliance was positively associated with being primiparous, older than 25 years and non-smoker [21]. Similarly, for about $16 \%$ of the births in our study, the mothers had followed the 
Table 3 Relative risks (RRs) with 95\% confidence intervals (95\% Cl) of adequate maternal periconceptional folic acid supplement use (before and during pregnancy) by combining maternal and paternal education in 683,785 pregnancies, Norway, 1999-2010

\begin{tabular}{|c|c|c|c|c|c|c|c|}
\hline \multirow[b]{2}{*}{ Maternal education } & \multirow[b]{2}{*}{ Paternal education } & \multicolumn{2}{|c|}{ Adequate folic acid use } & \multicolumn{2}{|c|}{ Unadjusted } & \multicolumn{2}{|c|}{ Adjusted $^{a}$} \\
\hline & & Yes & No & $\mathrm{RR}^{*}$ & $95 \% \mathrm{Cl}$ & $\mathrm{RR}^{*}$ & $95 \% \mathrm{Cl}$ \\
\hline \multirow[t]{4}{*}{ Compulsory education } & Compulsory education & 2557 & 48,326 & 0.46 & $0.43-0.50$ & 0.53 & $0.50-0.57$ \\
\hline & Intermediate education & 4758 & 52,693 & 0.77 & $0.72-0.81$ & 0.76 & $0.72-0.81$ \\
\hline & Tertiary education & 1292 & 10,651 & 1.00 & Reference & 1.00 & Reference \\
\hline & Missing information & 208 & 4994 & & & & \\
\hline \multirow[t]{4}{*}{ Intermediate education } & Compulsory education & 5079 & 43,708 & 0.60 & $0.57-0.62$ & 0.66 & $0.64-0.68$ \\
\hline & Intermediate education & 18,055 & 116,378 & 0.77 & $0.75-0.79$ & 0.81 & $0.79-0.83$ \\
\hline & Tertiary education & 7477 & 35,269 & 1.00 & Reference & 1.00 & Reference \\
\hline & Missing information & 426 & 3928 & & & & \\
\hline \multirow[t]{4}{*}{ Tertiary education } & Compulsory education & 3805 & 17,985 & 0.70 & $0.67-0.72$ & 0.75 & $0.73-0.77$ \\
\hline & Intermediate education & 22,150 & 80,373 & 0.86 & $0.85-0.87$ & 0.88 & $0.87-0.89$ \\
\hline & Tertiary education & 42,541 & 126,896 & 1.00 & Reference & 1.00 & Reference \\
\hline & Missing information & 747 & 3539 & & & & \\
\hline \multicolumn{2}{|c|}{ Missing data (maternal education) } & 28,179 & 1771 & & & & \\
\hline
\end{tabular}

${ }^{a}$ Adjusted for paternal age $(<20,20-24,25-29,30-34,35-39,40+)$, year of childbirth (1999-2010 (continuous)), paternal country of origin (Norway, high income countries, low/middle income countries), stratified by maternal education

${ }^{*} p$ values for interaction between maternal and paternal education were calculated by likelihood-ratio tests (unadjusted $p$ value $<0.001$; adjusted $\mathrm{p}$ value $<0.001$ )

national guidelines of FA use in the study period (1999-2010).

In Norway, a publication from the Norwegian Mother and Child Cohort Study (MoBa), comprising 27\% of the births registered in MBRN during 2000-2003, showed similar results to ours [22]. They found a positive association between paternal education and recommended periconceptional FA use. In pregnancies with fathers having university or college education the adjusted relative risk (RR) of periconceptional maternal FA use was 1.4 (95\% CI 1.1-1.8) compared to pregnancies with fathers with primary education. However, the association was weaker than for maternal education. When paternal tertiary education was compared to paternal compulsory education (reference) in our analyses, we found a similar result for adjusted RR of 1.45 (95\% CI 1.42-1.48).

Couples who live together share the same environment, social network, financial resources, and to some extent, the same health risk; beneficial or negative to health outcomes depending on the health behaviour of the spouses [25, 27]. Furthermore, a Dutch study of 40,000 individuals aged $25-74$ years showed that women seems more affected by their partner's educational level than men are with regard to healthy behaviour [41].

In accordance with our findings, a cross-sectional household survey conducted in Pakistan (comprising 6266 women), showed that maternal intake of iron and FA supplements was positively associated with the educational status of the mothers' husband [42].

The association of ethnic background and maternal periconceptional FA use have been studied in Norway and other European countries (Netherlands, Belgium, Ireland and the United Kingdom) [23, 43-46]. These studies show that supplement use is less common among most ethnic minority groups than among the comparison groups. We have similar findings in our study, showing a lower risk of adequate maternal FA use among fathers originating from low/middle-income countries.

The strengths of our study included use of comprehensive data from population-based registries in Norway that assures generalizability of our results, and registration of individual-level information on periconceptional FA intake for all births in Norway since 1999 (except for terminated pregnancies).

Our study had some limitations. Maternal FA intake could have been misclassified; in the beginning of the study period, FA users were underreported to the MBRN [47]. Our results may therefore be somewhat weaker than the true associations. Furthermore, we could not adjust for pregnancy planning, maternal physical activity or maternal use of alcohol $[16,18,20-24]$, as these potential confounders/covariates were not available in our dataset. However, a recent longitudinal study during 2014 on men's pregnancy planning comprising about 800 participants in Sweden, showed that $81 \%$ of the pregnancies were planned and the level of paternal education was positively associated with pregnancy planning [48]. Moreover, data from 22,500 mothers in the MoBa study with deliveries recorded in 2000-2003 showed that $78 \%$ of the mothers had planned their pregnancy [22]. However, MoBA is not entirely representative of the 
total pregnant population in Norway, since the participants are somewhat better educated, slightly older at delivery, and with a lower percentage of smokers than the overall pregnant population.

Information about fathers was not available in 12,699 births ( $2 \%$ of all births in the study population) and were excluded from the study population. They represent births with fathers unreported by the pregnant woman or fathers without identification number from the NR. Among the excluded births (missing father information), $10 \%$ of the mothers had adequate periconceptional FA supplementation (16\% in the study population) with an RR of 0.63 (95\% CI 0.60-0.66) for adequate maternal FA use comparing births with unregisterd fathers with births having registered fathers.

Adjusting for maternal confounders (maternal age, education, or country of origin) in our analysis reduced the strength of the associations between paternal determinants (age, education or country of origin) and adequate maternal periconceptional FA use. This suggest that paternal factors are important, but targeting maternal demographic and socioeconomic conditions and other factors related to low use is still important. However, our findings have implications for public health practice. Recent research on men's birth intentions has shown that $63 \%$ of pregnancies were intended (wanted) by the father [49]. Further, our study demonstrates the importance of the partner's impact on maternal reproductive health and family planning through shared decision-making.

\section{Conclusions}

In conclusion, our study supports the importance of father's prenatal role in their children's health. In order to improve maternal periconceptional FA supplementation use, information and knowledge about the importance of FA's preventive potential needs to be directed to both men and women. Furthermore, our findings show that women having partners originating from low/middle-income countries, partners at age $<30$ and $>34$ years, having compulsory education only, and having occupations other than "higher professional", compared to "lower professionals", are particularly susceptible to low periconceptional FA use. Therefore, campaigns for improved FA supplementation use should focus particularly on these groups.

\section{Abbreviations \\ BMI: Body mass index; DAGs: Directed acyclic graphs; IVF: In vitro fertilization; MBRN: Medical Birth Registry of Norway; MoBa: Norwegian Mother and Child Cohort Study; NAV: Norwegian Labour and Welfare Administration; NTDs: Neural tube defects; NUDB: Norwegian National Education Database}

\section{Acknowledgements}

The Norwegian Cancer Society, Western Norway Regional Health Authority, and the University of Bergen are acknowledged.

\section{Funding}

The Norwegian Cancer Society, Western Norway Regional Health Authority, project number 911629 to Dr. Nina Øyen, and the University of Bergen supported this study. The study sponsors had no role in the design, analysis, interpretation of data, or writing of this manuscript.

\section{Availability of data and materials}

Principal investigator, prof. Nina Øyen, sought and obtained all permissions to access data from the Medical Birth Registry of Norway (MBRN), the National Registry (NR), the Norwegian Labour and Welfare Administration, and the Norwegian National Education Database (NUDB). The datasets analysed during the current study are not freely available due to national regulations.

\section{Authors' contributions \\ $J H M$ conceived the study, performed all analyses, and led the writing. NØ and TB conceived the study and participated in manuscript preparation and writing. RMN participated in the analyses and writing. TF participated in the statistical analyses. ST participated in manuscript preparation. All authors helped to conceptualize ideas, interpret findings, and review drafts of the manuscript. All authors read and approved the final manuscript. No conflicts of interest are declared.}

\section{Ethics approval and consent to participate}

The study was approved by the Regional Committee for Medical and Health Research Ethics of Western Norway (REK ref. number 2010/3310).

\section{Competing interests}

The authors declare that they have no competing interests.

\section{Publisher's Note}

Springer Nature remains neutral with regard to jurisdictional claims in published maps and institutional affiliations.

\section{Author details}

'Department of Global Public Health and Primary Care, University of Bergen, Kalfarveien 31, N-5018 Bergen, Norway. ${ }^{2}$ Department of Obstetrics and Gynecology, Haukeland University Hospital, Bergen, Norway. ${ }^{3}$ Center for Medical Genetics and Molecular Medicine, Haukeland University Hospital, Bergen, Norway. ${ }^{4}$ Department of Health and Social Sciences, Western Norway University of Applied Sciences, Bergen, Norway. ${ }^{5}$ Cancer Registry of Norway, Oslo, Norway.

Received: 4 February 2017 Accepted: 15 May 2018

Published online: 30 May 2018

\section{References}

1. MRC. Prevention of neural tube defects: results of the Medical Research Council vitamin study. MRC vitamin study research group. Lancet. 1991; 338(8760):131-7.

2. Czeizel AE, Dudas I. Prevention of the first occurrence of neural-tube defects by periconceptional vitamin supplementation. N Engl J Med. 1992;327(26): 1832-5.

3. Berry RJ, Li Z, Erickson JD, Li S, Moore CA, Wang H, Mulinare J, Zhao P, Wong LY, Gindler J, et al. Prevention of neural-tube defects with folic acid in China. China-U.S. collaborative project for neural tube defect prevention. N Engl J Med. 1999;341(20):1485-90.

4. Scientific Advisory Committee on Nutrition. Folate and Disease Prevention. TSO (The Stationery Office), vol. 2006. London: Scientific Advisory Committee on Nutrition.

5. De-Regil LM, Pena-Rosas JP, Fernandez-Gaxiola AC, Rayco-Solon P. Effects and safety of periconceptional oral folate supplementation for preventing birth defects. Cochrane Database Syst Rev. 2015;12:CD007950.

6. Wagner C. Biochemical role of folate in cellular metabolism (reprinted from folate and health disease, pgs 23-42, 1995). Clin Res Regul Aff. 2001;18(3): $161-80$.

7. Sadler TWTW, Langman J. Langman's medical embryology, 11th ed. / T.W. Sadler; original illustrations by Jill Leland; computer illustrations by Susan L. Sadler-Redmond; scanning electron micrographs by Kathy Tosney; ultrasound images by Nancy Chescheir and Hytham Imseis. United States: Philadelphia: Wolters Kluwer Lippincott Williams \& Wilkins; 2010. 
8. Suren P, Roth C, Bresnahan M, Haugen M, Hornig M, Hirtz D, Lie KK, Lipkin WI, Magnus P, Reichborn-Kjennerud T, et al. Association between maternal use of folic acid supplements and risk of autism spectrum disorders in children. JAMA. 2013;309(6):570-7.

9. Roth C, Magnus P, Schjolberg S, Stoltenberg C, Suren P, McKeague IW, Davey Smith G, Reichborn-Kjennerud T, Susser E. Folic acid supplements in pregnancy and severe language delay in children. JAMA. 2011;306(14): 1566-73.

10. Nilsen RM, Vollset SE, Rasmussen SA, Ueland PM, Daltveit AK. Folic acid and multivitamin supplement use and risk of placental abruption: a populationbased registry study. Am J Epidemiol. 2008;167(7):867-74

11. Centers for disease control. Recommendations for the use of folic acid to reduce the number of cases of spina bifida and other neural tube defects. MMWR. 1992;41(RR-14):1-7.

12. National Council on Nutrition and Physical Activity. Recommendations and means to increase folate intake among women in fertile age [Anbefalinger og virkemidler for økt folatinntak blant kvinner i fertil alder]. Report no 1/ 1998. Oslo: National Council on Nutrition and Physical Activity [Statens Ernæringsråd]; 1998.

13. Nordic Nutrition Recommendations 2012. In: Integrating nutrition and physical activity. Edited by 2014 NCoM. 5th ed. Copenhagen; 2014. http:// dx.doi.org/10.6027/Nord2014-002.

14. Lumley J, Watson L, Watson M, Bower C. Periconceptional supplementation with folate and/or multivitamins for preventing neural tube defects. Cochrane Database Syst Rev. 2001;(3):CD001056. https://doi.org/10.1002/ 14651858.CD001056.

15. Daltveit AK, Vollset SE, Lande B, Oien H. Changes in knowledge and attitudes of folate, and use of dietary supplements among women of reproductive age in Norway 1998-2000. Scand J Public Health. 2004;32(4): 264-71

16. Bower C, Miller M, Payne J, Serna P. Promotion of folate for the prevention of neural tube defects: who benefits? Paediatr Perinat Epidemiol. 2005;19(6): 435-44.

17. Ministry of Health and Care Services. [National action plan for a better diet (2017-2021)] Nasjonal handlingsplan for bedre kosthold (2017-2021). In: Edited by omsorgsdepartementet MoHaCSH-o: Departementenes sikkerhets- og serviceorganisasjon; 2017. p. 57.

18. Nilsen RM, Mastroiacovo P, Gunnes N, Alsaker ER, Bjorke-Monsen AL, Eussen SJ, Haugen M, Johannessen A, Meltzer HM, Stoltenberg C, et al. Folic acid supplementation and interpregnancy interval. Paediatr Perinat Epidemiol. 2014:28(3):270-4.

19. Medical birth registry and abortion registry - statistical database [Medisinsk fødselsregister og abortregisteret - statistikkbanker] [http:// statistikk.fhi.no/mfr/]. Accessed 23 May 2018.

20. Cueto HT, Riis AH, Hatch EE, Wise LA, Rothman KJ, Mikkelsen EM. Predictors of preconceptional folic acid or multivitamin supplement use: a crosssectional study of Danish pregnancy planners. Clin Epidemiol. 2012:4:259-65.

21. Knudsen VK, Orozova-Bekkevold I, Rasmussen LB, Mikkelsen TB, Michaelsen KF, Olsen SF. Low compliance with recommendations on folic acid use in relation to pregnancy: is there a need for fortification? Public Health Nutr. 2004;7(7):843-50.

22. Nilsen RM, Vollset SE, Gjessing HK, Magnus P, Meltzer HM, Haugen M, Ueland PM. Patterns and predictors of folic acid supplement use among pregnant women: the Norwegian mother and child cohort study. Am J Clin Nutr. 2006;84(5):1134-41.

23. Timmermans S, Jaddoe WW, Mackenbach JP, Hofman A, SteegersTheunissen RP, Steegers EA. Determinants of folic acid use in early pregnancy in a multi-ethnic urban population in the Netherlands: the generation R study. Prev Med. 2008;47(4):427-32.

24. Braekke K, Staff AC. Periconceptional use of folic acid supplements in Oslo. Acta Obstet Gynecol Scand. 2003;82(7):620-7.

25. Jackson SE, Steptoe A, Wardle J. The influence of partner's behavior on health behavior change: the English longitudinal study of ageing. JAMA Intern Med. 2015;175(3):385-92.

26. Desrosiers A, Thompson A, Divney A, Magriples U, Kershaw T. Romantic partner influences on prenatal and postnatal substance use in young couples. J Public Health (Oxf). 2016;38(2):300-7.

27. Cornelius T, Desrosiers A, Kershaw T. Spread of health behaviors in young couples: how relationship power shapes relational influence. Soc Sci Med. 2016:165:46-55.
28. Irgens LM. The medical birth registry of Norway. Epidemiological research and surveillance throughout 30 years. Acta Obstet Gynecol Scand. 2000; 79(6):435-9.

29. Kinge JM, Steingrimsdottir OA, Moe JO, Skirbekk V, Naess O, Strand BH. Educational differences in life expectancy over five decades among the oldest old in Norway. Age Ageing. 2015;

30. Hammer $\mathrm{H}$. The central population registry in medical research. Tidsskr Nor Laegeforening. 2002;122(26):2550.

31. STYRK-08: [Standard Classification of Occupations (STYRK-08)] Standard for yrkesklassifisering (STYRK-08). In: Notater. Oslo-Kongsvinger: Statistics Norway; 2011. ISSN 1891-5906. https://www.ssb.no/en/.

32. Vangen T: Nasjonal utdanningsdatabase NUDB. 2007

33. Erikson R, Goldthorpe JH. The constant flux: a study of class mobility in industrial societies: Oxford University Press, USA; 1992.

34. Global Health Estimates 2015: Disease burden by Cause, Age, Sex, by Country and by Region, 2000-2015. Geneva: World Health Organization; 2016

35. Shrier I, Platt RW. Reducing bias through directed acyclic graphs. BMC Med Res Methodol. 2008;8(1):70

36. Textor J, Hardt J, Knuppel S. DAGitty: a graphical tool for analyzing causal diagrams. Epidemiology. 2011;22(5):745.

37. Pearl J. An introduction to causal inference. Int J Biostat. 2010;6(2):Article 7.

38. Nilsen RM, Leoncini E, Gastaldi P, Allegri V, Agostino R, Faravelli F, Ferrazzoli F, Finale E, Ghirri P, Scarano G, et al. Prevalence and determinants of preconception folic acid use: an Italian multicenter survey. Ital J Pediatr. 2016;42(1):1-10.

39. StataCorp. Stata Statistical Software: Release 15. College Station. TX: StataCorp LLC; 2017

40. Cameron AC, Miller DL. A Practitioner's guide to cluster-robust inference. J Hum Resour. 2015;50(2):317-73.

41. Monden CW, van Lenthe F, de Graaf ND, Kraaykamp G. Partner's and own education: does who you live with matter for self-assessed health, smoking and excessive alcohol consumption? Soc Sci Med. 2003:57(10):1901-12.

42. Nisar YB, Dibley MJ, Mir AM. Factors associated with non-use of antenatal iron and folic acid supplements among Pakistani women: a cross sectional household survey. BMC Pregnancy Childbirth. 2014;14:305.

43. Kinnunen TI, Sletner L, Sommer C, Post MC, Jenum AK. Ethnic differences in folic acid supplement use in a population-based cohort of pregnant women in Norway. BMC Pregnancy Childbirth. 2017;17(1):143.

44. Baraka MA, Steurbaut S, Leemans L, Foulon W, Laubach M, Coomans D, Jansen E, Dupont AG. Determinants of folic acid use in a multi-ethnic population of pregnant women: a cross-sectional study. J Perinat Med. 2011;39(6):685-92.

45. McGuire M, Cleary B, Sahm L, Murphy DJ. Prevalence and predictors of periconceptional folic acid uptake-prospective cohort study in an Irish urban obstetric population. Hum Reprod. 2010;25(2):535-43.

46. Brough L, Rees GA, Crawford MA, Dorman EK. Social and ethnic differences in folic acid use preconception and during early pregnancy in the UK: effect on maternal folate status. J Hum Nutr Diet. 2009;22(2):100-7.

47. Nilsen RM, Vollset SE, Gjessing HK, Skjaerven R, Melve KK, Schreuder P, Alsaker ER, Haug K, Daltveit AK, Magnus P. Self-selection and bias in a large prospective pregnancy cohort in Norway. Paediatr Perinat Epidemiol. 2009; 23(6):597-608

48. Bodin M, Kall L, Tyden T, Stern J, Drevin J, Larsson M. Exploring men's pregnancy-planning behaviour and fertility knowledge:a survey among fathers in Sweden. Ups J Med Sci. 2017;122(2):127-35.

49. Lindberg LD, Kost K. Exploring U.S. men's birth intentions. Matern Child Health J. 2014;18(3):625-33. 